
\title{
28 Research Square \\ Impact of anemia on in-stent restenosis after percutaneous coronary intervention
}

\section{Huilin $\mathrm{Hu}$}

Affiliated Hospital of Jiaxing University

\section{Shijun Wang}

Affiliated Hospital of Jiaxing University

\section{Guanmin Tang}

Affiliated Hospital of Jiaxing University

Changlin Zhai

Affiliated Hospital of Jiaxing University

Liang Shen ( $\nabla$ shenliang8011@126.com )

Affiliated Hospital of Jiaxing University

\section{Research Article}

Keywords: anemia, in-stent restenosis, percutaneous coronary intervention

Posted Date: April 14th, 2021

DOI: https://doi.org/10.21203/rs.3.rs-403286/v1

License: (c) (1) This work is licensed under a Creative Commons Attribution 4.0 International License. Read Full License

Version of Record: A version of this preprint was published at BMC Cardiovascular Disorders on November 19th, 2021. See the published version at https://doi.org/10.1186/s12872-021-02355-1. 


\section{Abstract}

Background Anemia is a well-recognized risk factor for adverse events after percutaneous coronary intervention (PCl), but data regarding the association between anemia and in-stent restenosis (ISR) remain limited.

Methods A total of 538 patients who underwent PCl between January 2018 and September 2019 and performed follow-up angiography 9-12 months after the initial PCI was enrolled in the study. Baseline clinical and procedural characteristics were compared between ISR and non-ISR group. Multivariate logistic regression analysis was employed to determine the independent predictors of ISR.

Results The incidence of anemia in patients with ISR was 53.5\% and 19.0\% in the non-ISR group, which was significantly different ( $P \llbracket 0.001)$. The rate of diabetes, chronic kidney disease (CKD), bifurcation lesion and calcification was significantly higher in ISR group. In addition, low-density lipoprotein cholesterol (LDL-C), multiple stenting and stent diameter were also significantly related with ISR. After multivariate logistic analysis, anemia (odds ratio [OR], 2.786; 95\% confidence interval [CI], 1.091 to 7.115; $\mathrm{P}=0.032)$ together with $\mathrm{LDL}-\mathrm{c}(\mathrm{OR}, 1.682 ; 95 \% \mathrm{Cl}, 1.145$ to $2.469 ; \mathrm{P}=0.008)$, diabetes $(\mathrm{OR}, 3.582 ; 95 \% \mathrm{Cl}$, 1.406 to $9.125 ; P=0.007)$, $C K D(O R, 2.841 ; 95 \% \mathrm{Cl}, 1.006$ to $8.027 ; P=0.049)$, multiple stenting (OR, 2.823; $95 \% \mathrm{Cl}, 1.184$ to $6.731 ; \mathrm{P}=0.019)$, and stent diameter $(\mathrm{OR}, 2.778 ; 95 \% \mathrm{Cl}, 1.069$ to $7.194 ; \mathrm{P}=0.036)$ were closely associated with ISR.

Conclusion Anemia is closely associated with ISR after PCl, patients with lower hemoglobin have a higher risk of ISR.

\section{Introduction}

Percutaneous coronary intervention (PCI) has become an effectively and widely used treatment for patients with coronary artery disease (CAD) since 1979[1]. Despite on-going improvement of drug-eluting stent (DES), in-stent restenosis (ISR) remains one of the major complications of $\mathrm{PCl}$, which accounts for approximately $5 \%[2,3]$. The factors involved in the development of ISR are multiple, including inflammatory response, patient-specific and procedure-related risk factors[4].

Anemia is found to be associated with a greater rate of cardiovascular events $[5,6]$. The prevalence of anemia is comparatively high in patients with CAD. Previous studies have demonstrated that anemia is related to a higher risk of death, major adverse cardiovascular events (MACE), myocardial infarction (MI), and bleeding after PCI[7-10].

Although studies have shown that anemia is associated with fatal adverse events post PCl, data is lacking regarding the relation between anemia and ISR. In this study, we explored whether anemia was associated with ISR and could be used as an independent predictor of ISR after PCI in patients with CAD.

\section{Materials And Methods}




\section{Patients and study design}

This was a retrospective observational cohort study carried out at the First Hospital of Jiaxing. Our study followed the principles of the Declaration of Helsinki and was approved by the Ethics Committee at the First Hospital of Jiaxing, Jiaxing, China. A total of 538 CAD patients were treated with second-generation DES between January 2017 and September 2019 and performed followed-up angiography 9-12 months after the initial $\mathrm{PCl}$ in our hospital were enrolled, and written informed consent was obtained from all patients. Patients with major adverse cardiac events(death, stroke, repeated $\mathrm{PCl}$ ) after $\mathrm{PCl}$, severe infection, malignancy, severe chronic kidney disease(estimated glomerular filtration rate $[\mathrm{eGFR}]<30$ $\mathrm{ml} / \mathrm{min} / 1.73 \mathrm{~m}^{2}$ ), severe anemia (hemoglobin levels $<6 \mathrm{~g} / \mathrm{dL}$ ), active liver disease, and coagulation disorders were excluded.

The initial assessments of the patients included a medical history, pharmacotherapy, angiographic characteristics and blood biochemistry tests for a complete blood cell count, low-density lipoprotein cholesterol (LDL-c) and triglycerides (TG). Anemia was defined as a baseline hemoglobin( $\mathrm{Hb}$ ) levels $<12$ $\mathrm{g} / \mathrm{dL}$.

\section{$\mathrm{PCl}$ procedures and follow-up evaluations}

$\mathrm{PCl}$ was performed as described earlier, and DES were implanted in all patients according to the current guidelines. All patients received dual antiplatelet therapy before and after the procedures. The follow-up angiography was performed 9-12 months after the initial PCl. The evaluation of restenosis was carried out using the conventional QCA technique. ISR was defined as a luminal narrowing with more than $50 \%$ diameter stenosis of a stented coronary segment or within a $5 \mathrm{~mm}$ segment proximal or distal to the stent[11].

\section{Statistical analysis}

All statistical analyses were carried out using IBM SPSS 22.0. Data for continuous variables are expressed as mean $\pm S D$ and categorical variables as percentages. Continuous variables were analyzed by $t$-test and categorical variables by $\chi 2$-test. A one-way ANOVA analysis was used to determine differences among different categories of $\mathrm{Hb}$. A two tailed $\mathrm{P}$ value less than 0.05 was considered statistically significant. Binary logistic regression analysis was performed to assess the risk factors of ISR. Odds ratio (OR) and 95\% confidence interval $(\mathrm{Cl})$ were calculated. To analyze the influence of covariates on the relation between anemia and ISR, we carried out multivariate logistic regression analysis. Only those variables with statistical significance set at $\mathrm{P}$ less than 0.05 at univariate analysis together with age and gender were included in a multivariate logistic regression model to determine the independent predictors of ISR[12]. Moreover, we also performed a receiver operating characteristics (ROC) curve analysis to describe the accuracy of $\mathrm{Hb}$ for prediction of ISR.

\section{Results}

General characteristics of the patients with and without ISR 
Among the 538 subjects included in the study, 28 patients (5.2\%) suffered ISR, and 20 patients underwent repeat revascularization with the assistance of intravascular ultrasound (IVUS), the baseline characteristics are summarized in Table 1. Overall, patients were 62.2 \pm 10.2 years of age (range 29-87 years) and $71.4 \%$ were male. Compared with non-ISR group, patients with ISR more frequently had a higher LDL-c level and lower $\mathrm{Hb}$ level. The rate of co-morbidities, including diabetes, anemia, chronic kidney disease (CKD) was significantly higher in ISR group ( $P$ values $0.015, \varangle 0.001,0.008$, respectively). Angiographic findings showed that the prevalence of multiple stenting, smaller diameters stent implanted, bifurcation and calcification was significantly higher in patients with ISR ( $P$ values 0.012 , $0.007,0.010,0.045$, respectively). 
Table 1

Baseline and procedural characteristics

\begin{tabular}{|c|c|c|c|}
\hline Variable & ISR $(n=28)$ & Non-ISR $(n=510)$ & P Value \\
\hline Male, n(\%) & $18(64.3)$ & $366(71.7)$ & 0.394 \\
\hline Age(years) & $62.5 \pm 12.3$ & $62.2 \pm 10.1$ & 0.102 \\
\hline Current smoker, n (\%) & $12(42.9)$ & $221(43.3)$ & 0.961 \\
\hline BMI (kg/m2) & $23.7 \pm 3.3$ & $24.5 \pm 2.8$ & 0.411 \\
\hline Hypertension, n(\%) & $17(60.7)$ & $330(61.3)$ & 0.667 \\
\hline Diabetes mellitus, n(\%) & $11(39.3)$ & $102(20.0)$ & 0.015 \\
\hline LDL-c (mmol/L) & $3.1 \pm 1.6$ & $2.6 \pm 0.9$ & 0.002 \\
\hline $\mathrm{TG}(\mathrm{mmol} / \mathrm{L})$ & $1.5 \pm 0.6$ & $1.6 \pm 0.9$ & 0.187 \\
\hline $\mathrm{Hb}(\mathrm{g} / \mathrm{dL})$ & $115.4 \pm 20.1$ & $134.9 \pm 21.3$ & $\nabla 0.001$ \\
\hline LVEF (\%) & $57.5 \pm 7.9$ & $60.0 \pm 6.6$ & 0.051 \\
\hline Anemia (\%) & $15(53.5)$ & $97(19.0)$ & 0.001 \\
\hline CKD (\%) & $8(28.6)$ & $59(11.6)$ & 0.008 \\
\hline ACS (\%) & $15(53.6)$ & $280(54.9)$ & 0.890 \\
\hline Multiple stenting, $\mathrm{n}(\%)$ & 14 & 142 & 0.012 \\
\hline Stent length (mm) & $28.8 \pm 6.1$ & $29.6 \pm 5.4$ & 0.457 \\
\hline Stent diameter $(\mathrm{mm})$ & $2.9 \pm 0.4$ & $3.2 \pm 0.5$ & 0.007 \\
\hline Multivessel coronary disease (\%) & $6(21.4)$ & $96(18.8)$ & 0.732 \\
\hline LMCA, n(\%) & $2(7.1)$ & $10(2.0)$ & 0.071 \\
\hline LAD, n(\%) & $7(25.0)$ & $75(14.7)$ & 0.140 \\
\hline LCX, n(\%) & $18(64.2)$ & $230(45.1)$ & 0.053 \\
\hline RCA, n(\%) & $7(25.0)$ & $202(39.6)$ & 0.123 \\
\hline Bifurcation lesion, n(\%) & $13(46.4)$ & $125(24.5)$ & 0.010 \\
\hline Calcification, n(\%) & $4(14.3)$ & $23(4.5)$ & 0.045 \\
\hline Statins, $n(\%)$ & 26 (92.9) & 483 (94.7) & 0.673 \\
\hline
\end{tabular}

Abbreviation: ISR, In-stent restenosis; BMI, Body mass index; CKD, Chronic kidney disease; $\mathrm{Hb}$, hemoglobin; LVEF, Left ventricular ejection fraction; ACS, Acute coronary syndrome; LDL-C, Lowdensity lipoprotein cholesterol; TG, triglycerides; LMCA, Left main conronary artery; LAD, Left anterior descending artery; LCX, Left circumflex artey; RCA, Right coronary artery 


\begin{tabular}{|llll|}
\hline Variable & ISR $(\mathbf{n = 2 8 )}$ & Non-ISR $(\mathbf{n = 5 1 0 )}$ & P Value \\
\hline Aspirin, $\mathrm{n}(\%)$ & $28(100)$ & $502(98.4)$ & 0.504 \\
\hline Clopidogrel, $\mathrm{n}(\%)$ & $15(53.6)$ & $253(49.6)$ & 0.683 \\
\hline Ticagrelor, $\mathrm{n}(\%)$ & $10(35.7)$ & $227(44.5)$ & 0.361 \\
\hline $\begin{array}{l}\text { Abbreviation: ISR, In-stent restenosis; BMI, Body mass index; CKD, Chronic kidney disease; Hb, } \\
\text { hemoglobin; LVEF, Left ventricular ejection fraction; ACS, Acute coronary syndrome; LDL-C, Low- } \\
\text { density lipoprotein cholesterol; TG, triglycerides; LMCA, Left main conronary artery; LAD, Left anterior } \\
\text { descending artery; LCX, Left circumflex artey; RCA, Right coronary artery }\end{array}$ & \\
\hline
\end{tabular}

\section{Relationship between baseline $\mathrm{Hb}$ and the occurrence of ISR}

We divided the patients into three groups according to the baseline of $\mathrm{Hb}$ level before the initial $\mathrm{PCl}$ (Moderate anemia: $\nabla 9 \mathrm{~g} / \mathrm{dL}$; Mild anemia: $\geq 9$ and $\otimes 12 \mathrm{~g} / \mathrm{dL}$; and nonanemia group: $\geq 12 \mathrm{~g} / \mathrm{dL}$ ) to explore the relationship between the baseline $\mathrm{Hb}$ and the ISR at follow-up. The clinical and angiographic characteristics were compared among different $\mathrm{Hb}$ groups (Table 2). Anemia was present in $20.8 \%$ of all patient. We found that the patients with lower $\mathrm{Hb}$ were more likely to develop ISR (Moderate anemia: 26.3; Mild anemia: 8.6; and nonanemia :3.5; $\mathrm{P}<0.001$ ). Patients with anemia were more likely had CKD and discontinue the use of aspirin. 
Table 2

Clinical characteristics of different hemoglobin categories

\begin{tabular}{|c|c|c|c|c|}
\hline Variable & $\begin{array}{l}\text { Moderate anemia(n } \\
=19)\end{array}$ & $\begin{array}{l}\text { Mild anemia ( } n \\
=93 \text { ) }\end{array}$ & $\begin{array}{l}\text { Nonanemia }(n= \\
\text { 426) }\end{array}$ & $\mathbf{P}$ \\
\hline $\mathrm{Hb}(\mathrm{g} / \mathrm{dL})$ & $83.3 \pm 5.1$ & $104.9 \pm 6.2$ & $142.5 \pm 14.4$ & $\nabla 0.001$ \\
\hline Male(n) & $16(84.2)$ & $63(67.7)$ & 305 (71.6) & 0.344 \\
\hline Age(years) & $66.0 \pm 12.8$ & $63.3 \pm 10.4$ & $61.8 \pm 10.0$ & 0.106 \\
\hline Current smoker (\%) & $9(47.4)$ & $40(43.0)$ & $184(43.2)$ & 0.936 \\
\hline BMI (kg/m2) & $24.6 \pm 2.6$ & $24.4 \pm 2.9$ & $24.5 \pm 2.8$ & 0.922 \\
\hline Hypertension(\%) & $13(68.4)$ & $63(67.7)$ & $271(63.6)$ & 0.706 \\
\hline Diabetes mellitus (\%) & $5(26.3)$ & 25 (26.9) & $83(19.5)$ & 0.241 \\
\hline LDL-c(mmol/L) & $2.6 \pm 1.1$ & $2.5 \pm 0.9$ & $2.6 \pm 0.9$ & 0.805 \\
\hline TG(mmol/L) & $1.7 \pm 0.9$ & $1.5 \pm 0.8$ & $1.6 \pm 0.9$ & 0.531 \\
\hline LVEF(\%) & $56.8 \pm 6.3$ & $60.2 \pm 6.3$ & $59.9 \pm 6.8$ & 0.113 \\
\hline CKD (\%) & $9(47.4)$ & $13(14.0)$ & $45(10.6)$ & $\nabla 0.001$ \\
\hline ACS (\%) & $11(57.9)$ & $51(54.8)$ & $233(54.7)$ & 0.963 \\
\hline Multiple stenting(\%) & $3(15.8)$ & 31 (33.3) & $122(28.6)$ & 0.290 \\
\hline Stent length(mm) & $28.3 \pm 4.9$ & $29.4 \pm 5.1$ & $29.6 \pm 5.6$ & 0.557 \\
\hline Stent diameter(mm) & $3.0 \pm 0.5$ & $3.1 \pm 0.4$ & $3.2 \pm 0.4$ & 0.207 \\
\hline $\begin{array}{l}\text { Multivessel coronary } \\
\text { disease }(\%)\end{array}$ & $3(15.8)$ & $12(12.9)$ & $87(20.4)$ & 0.231 \\
\hline LMCA(\%) & 0 & 0 & $12(2.8)$ & 0.200 \\
\hline LAD(\%) & $2(10.5)$ & $8(8.6)$ & 72 (16.9) & 0.111 \\
\hline LCX(\%) & $8(42.1)$ & $47(50.5)$ & $193(45.3)$ & 0.618 \\
\hline RCA(\%) & $10(52.6)$ & 37 (39.8) & $162(38.0)$ & 0.434 \\
\hline Bifurcation lesion(\%) & $3(15.8)$ & $23(24.7)$ & 112(26.3) & 0.578 \\
\hline Calcification (\%) & 0 & $7(7.5)$ & $20(4.7)$ & 0.314 \\
\hline Statins (\%) & 19 (100) & 88 (94.6) & 402 (94.4) & 0.569 \\
\hline
\end{tabular}

Abbreviation: $\mathrm{Hb}$, hemoglobin; BMI, Body mass index; CKD, Chronic kidney disease; LVEF, Left ventricular ejection fraction; ACS, Acute coronary syndrome; LDL-c, Low-density lipoprotein cholesterol; TG, triglycerides; LMCA, Left main conronary artery; LAD, Left anterior descending artery; LCX, Left circumflex artey; RCA, Right coronary artery; ISR, In-stent restenosis; 


\begin{tabular}{|c|c|c|c|c|}
\hline Variable & $\begin{array}{l}\text { Moderate anemia(n } \\
=19)\end{array}$ & $\begin{array}{l}\text { Mild anemia ( } \\
=93 \text { ) }\end{array}$ & $\begin{array}{l}\text { Nonanemia }(n= \\
\text { 426) }\end{array}$ & $P$ \\
\hline Aspirin(\%) & 17 (89.5) & $90(96.7)$ & 423 (99.3) & $\nabla 0.001$ \\
\hline Clopidogrel (\%) & $8(42.1)$ & $48(51.6)$ & 212 (49.8) & 0.752 \\
\hline Ticagrelor(\%) & $7(36.8)$ & $40(43.0)$ & $190(44.6)$ & 0.782 \\
\hline ISR(\%) & $5(26.3)$ & $8(8.6)$ & $15(3.5)$ & $\nabla 0.001$ \\
\hline \multicolumn{5}{|c|}{$\begin{array}{l}\text { Abbreviation: Hb, hemoglobin; BMI, Body mass index; CKD, Chronic kidney disease; LVEF, Left } \\
\text { ventricular ejection fraction; ACS, Acute coronary syndrome; LDL-C, Low-density lipoprotein } \\
\text { cholesterol; TG, triglycerides; LMCA, Left main conronary artery; LAD, Left anterior descending artery; } \\
\text { LCX, Left circumflex artey; RCA, Right coronary artery; ISR, In-stent restenosis; }\end{array}$} \\
\hline
\end{tabular}

\section{Predictors of ISR at follow-up}

Binary logistic regression analysis was used to assess predictors of ISR at follow-up. All variables that were potentially correlated and clinically important were included in the univariate logistic model (Table 3). We found that diabetes, anemia, CKD, higher LDL-c were the significant predictors of the ISR ( $P$ value $0.018, \varangle 0.001,0.011 \rrbracket 0.003 \rrbracket$ respectively). Additional, multiple stenting, smaller stent diameter, bifurcation lesion and calcification were also significantly associated with ISR ( $P$ value $0.015 \varangle 0.009 \otimes 0.012,0.030$, respectively ). Then we applied multivariate logistic regression analysis that included all the significant univariate predictors found in Table 3 together with age and gender to determine the independent predictors of ISR. As a result, anemia was found to be an independent risk factor for ISR after adjustment for other confounding factors (OR:2.786, 95\% Cl: 1.091-7.115; P = 0.032) (Table 4). Besides, LDL-c (OR, 1.682; 95\% Cl, 1.145 to 2.469; $\mathrm{P}=0.008)$, diabetes (OR, 3.582; $95 \% \mathrm{Cl}, 1.406$ to $9.125 ; \mathrm{P}=0.007), \mathrm{CKD}(\mathrm{OR}, 2.841 ; 95 \% \mathrm{Cl}, 1.006$ to $8.027 ; \mathrm{P}=0.049)$, multiple stenting (OR, 2.823; $95 \%$ $\mathrm{Cl}, 1.184$ to $6.731 ; \mathrm{P}=0.019)$, stent diameter $(\mathrm{OR}, 2.778 ; 95 \% \mathrm{Cl}, 1.069$ to $7.194 ; \mathrm{P}=0.036)$ and bifurcation lesion (OR, 2.459; $95 \% \mathrm{Cl}, 1.020$ to $5.926 ; \mathrm{P}=0.045$ ) also were independent predictors of ISR at follow-up. ROC curve analysis of the diagnostic accuracy of the $\mathrm{Hb}$ for ISR showed an area under the curve (AUC) of $0.758(95 \% \mathrm{Cl}, 0.675$ to $0.840 ; \mathrm{P}<0.001)$ (Fig. 1). 
Table 3

Univariable logistic regression analysis for the prediction of ISR

\begin{tabular}{|c|c|c|c|}
\hline Variable & OR & $95 \% \mathrm{Cl}$ & P Vaule \\
\hline Gender & 0.708 & $0.319-1.571$ & 0.396 \\
\hline Age & 1.003 & $0.967-1.042$ & 0.858 \\
\hline Current smoker & 1.020 & $0.473-2.199$ & 0.961 \\
\hline BMI & 0.908 & $0.788-1.046$ & 0.179 \\
\hline Hypertension & 1.186 & $0.544-2.587$ & 0.668 \\
\hline Diabetes mellitus & 2.588 & $1.176-5.696$ & 0.018 \\
\hline LDL-C & 1.651 & $1.187-2.296$ & 0.003 \\
\hline TG & 0.813 & $0.489-1.353$ & 0.426 \\
\hline LVEF & 0.958 & $0.916-1.001$ & 0.057 \\
\hline Anemia & 4.283 & $1.949-9.410$ & $\bowtie 0.001$ \\
\hline CKD & 3.058 & $1.289-7.252$ & 0.011 \\
\hline ACS & 0.948 & $0.442-2.033$ & 0.890 \\
\hline Multiple stenting & 2.592 & $1.205-5.573$ & 0.015 \\
\hline Stent length(mm) & 0.974 & $0.908-1.044$ & 0.456 \\
\hline Stent diameter(mm) & 3.413 & $1.361-8.547$ & 0.009 \\
\hline Multivessel coronary disease & 1.176 & $0.464-2.980$ & 0.732 \\
\hline LMCA & 3.846 & $0.801-18.460$ & 0.092 \\
\hline LAD & 1.933 & $0.794-4.707$ & 0.146 \\
\hline LCX & 2.191 & $0.992-4.840$ & 0.052 \\
\hline RCA & 0.508 & $0.212-1.218$ & 0.129 \\
\hline Bifurcation lesion & 2.669 & $1.236-5.763$ & 0.012 \\
\hline Calcification & 3.529 & $1.131-11.014$ & 0.030 \\
\hline Statins & 0.727 & $0.164-3.223$ & 0.674 \\
\hline Aspirin & NA & NA & NA \\
\hline
\end{tabular}

Abbreviation: ISR, In-stent restenosis; BMI, Body mass index; CKD, Chronic kidney disease; LVEF, Left ventricular ejection fraction; ACS, Acute coronary syndrome; LDL-C, Low-density lipoprotein cholesterol; TG, triglycerides; LMCA, Left main conronary artery; LAD, Left anterior descending artery; LCX, Left circumflex artey; RCA, Right coronary artery 


\begin{tabular}{|c|c|c|c|}
\hline Variable & OR & $95 \% \mathrm{Cl}$ & P Vaule \\
\hline Clopidogrel & 0.853 & $0.397-1.828$ & 0.683 \\
\hline Ticagrelor & 0.693 & $0.314-1.530$ & 0.364 \\
\hline \multicolumn{4}{|c|}{$\begin{array}{l}\text { Abbreviation: ISR, In-stent restenosis; BMI, Body mass index; CKD, Chronic kidney disease; LVEF, Lef } \\
\text { ventricular ejection fraction; ACS, Acute coronary syndrome; LDL-C, Low-density lipoprotein } \\
\text { cholesterol; TG, triglycerides; LMCA, Left main conronary artery; LAD, Left anterior descending artery } \\
\text { LCX, Left circumflex artey; RCA, Right coronary artery }\end{array}$} \\
\hline
\end{tabular}

Table 4

Independent predictors of ISR by multivariable logistic regression analysis

\begin{tabular}{|llll|}
\hline Variable & OR & $\mathbf{9 5 \%} \mathrm{Cl}$ & P Vaule \\
\hline Gender & 0.599 & $0.239-1.501$ & 0.274 \\
\hline Age & 1.002 & $0.961-1.045$ & 0.919 \\
\hline Diabetes mellitus & 3.582 & $1.406-9.125$ & 0.007 \\
\hline LDL-c & 1.682 & $1.145-2.469$ & 0.008 \\
\hline Anemia & 2.786 & $1.091-7.115$ & 0.032 \\
\hline CKD & 2.841 & $1.006-8.027$ & 0.049 \\
\hline Multiple stenting & 2.823 & $1.184-6.731$ & 0.019 \\
\hline Stent diameter(mm) & 2.778 & $1.069-7.194$ & 0.036 \\
\hline Bifurcation lesion & 2.459 & $1.020-5.926$ & 0.045 \\
\hline Calcification & 3.356 & $0.896-12.572$ & 0.072 \\
\hline
\end{tabular}

\section{Discussion}

In the present study, we found that anemia was strongly associated with the occurrence of ISR and might be used as an independent predictor of ISR at follow-up. Although it is widely recognized that preprocedural anemia is associated with poor outcomes after PCl in patients with CAD, data about the impact of anemia on ISR at follow-up is insufficient.

Catakoglu et al. [13]demonstrated that anemia is an important risk factor for predicting nonfatal coronary events after $\mathrm{PCl}$, which included ST-segment elevation MI, non ST-segment elevation Ml, target-vessel revascularization (TVR) and target- lesion revascularization (TLR). While Geng et al. [12]found no statistic significant relation between low hemoglobin and ISR. In our research, after adjustment for 
confounding factors, a strong relation between anemia and ISR was revealed, indicating that anemic patients were more likely develop ISR after PCI.

The mechanisms of ISR in patients who have anemia and undergo PCl are not wellknown and probably multifactorial. The presence of anemia may lead to decreased supply of oxygen, and hypoxia has been identified with vascular cell proliferation and angiogenesis[14], which are necessary for the development, maintenance, and expansion of the neointimal lesions present in restenosis[15-17]. In addition, compensatory consequences of hypoxia, such as a hyperdynamic state with increased cardiac output, left ventricular hypertrophy and progressive cardiac enlargement, and, a proatherogenic role also contribute to the restenosis[18]. Moreover, anemia was found independently correlated with high platelet reactivity in patients with DES PCI[19], which have been shown contribute to the development of restenosis[20, 21].

Our data also showed that higher LDL-c, multiple stenting, bifurcation lesion and smaller stent diameter are associated with ISR after PCl, which is supported by previous studies[22-24]. Smoking is known to be a risk factor for CAD, but our data showed no significant relation between smoking and ISR. Interestingly, some studies supported that smoking is associated with a lower rate of restenosis, although still controversial[25]. Diabetes mellitus was considered as the most-consistent clinical parameter that increase the risk of restenosis[26, 27], which is accordance with our data. Several studies have explored the impact of CKD on ISR after PCl, end-stage renal disease might increase the risk for restenosis[28], while mild or moderate CKD had no impact on the incidence of ISR post-PCI[29], which is inconsistent with our results. In our study, patients with CKD are more likely combined with anemia, which may explain the different outcome.

In the present study, there're several limitations. First, it was retrospective in nature. Second, the sample size was relatively small and the follow-up period was relatively short. Third, our findings were based on a single measurement of preprocedural $\mathrm{Hb}$ level, the $\mathrm{Hb}$ during the follow-up were not evaluated. Large prospective trials are needed to confirm whether anemia can act as an independent predictor of ISR.

\section{Conclusion}

Patients with baseline anemia before $\mathrm{PCl}$ have a higher incidence of ISR after PCl compared with nonanemic counterparts. Anemia can be used as a predictor of ISR. Our results have important clinical implications and assessment of $\mathrm{Hb}$ level is crucial during periprocedural.

\section{List Of Abbreviations}

$\mathrm{Hb}$, hemoglobin; BMI, Body mass index; CKD, Chronic kidney disease; LVEF, Left ventricular ejection fraction; ACS, Acute coronary syndrome; LDL-c, Low-density lipoprotein cholesterol; TG, triglycerides; ISR, In-stent restenosis; 


\section{Declarations}

\section{Ethics approval and informed consent}

The study followed the principles of the Declaration of Helsinki and approved by the Ethics Committee of the First Hospital of Jiaxing (No. LS-2020-124). All participated in the study signed their consent after being fully informed of the purpose of research.

\section{Consent for publication}

Not applicable

\section{Availability of data and materials}

The data and material are available in the hospital information system (HIS) of our hospital.

\section{Competing interests}

The authors declare no competing interests.

\section{Funding}

This study was supported by Key Medicine Disciplines Co-construction Project of Jiaxing Municipal (To Guan-min Tang, Grant No. 2019-ss-xxgbx)

\section{Authors' contribution}

Huilin Hu: Conceptualization, Methodology; Shijun Wang: Formal analysis; Guanmin Tang: Supervision; Changlin Zhai: Investigation; Liang Shen: Conceptualization, Writing- Review and Editing

\section{Acknowledgements}

We thank the patients and their families involved in this study. We thank all the staff of catheterization lab for their registration of patient's information.

\section{References}

1. Gruntzig AR, Senning A, Siegenthaler WE: Nonoperative dilatation of coronary-artery stenosis: percutaneous transluminal coronary angioplasty. N Engl J Med 1979, 301(2):61-68.

2. Cassese S, Byrne RA, Tada T, Pinieck S, Joner M, Ibrahim T, King LA, Fusaro M, Laugwitz KL, Kastrati $A$ : Incidence and predictors of restenosis after coronary stenting in 10004 patients with surveillance angiography. Heart 2014, 100(2):153-159.

3. Tsai ML, Hsieh MJ, Chen CC, Chang SH, Wang CY, Chen DY, Yang CH, Yeh JK, Ho MY, Hsieh IC: Comparison of 9-Month Angiographic Follow-Up and Long-Term Clinical Outcomes of Biodegradable 
Polymer Drug-Eluting Stents and Second-Generation Durable Polymer Drug-Eluting Stents in Patients Undergoing Single Coronary Artery Stenting. Acta Cardio/ Sin 2020, 36(2):97-104.

4. Jukema JW, Verschuren JJ, Ahmed TA, Quax PH: Restenosis after PCl. Part 1: pathophysiology and risk factors. Nat Rev Cardio/ 2011, 9(1):53-62.

5. da Silveira AD, Ribeiro RA, Rossini AP, Stella SF, Ritta HA, Stein R, Polanczyk CA: Association of anemia with clinical outcomes in stable coronary artery disease. Coron Artery Dis 2008, 19(1):21-26.

6. Sabatine MS, Morrow DA, Giugliano RP, Burton PB, Murphy SA, McCabe CH, Gibson CM, Braunwald $\mathrm{E}$ : Association of hemoglobin levels with clinical outcomes in acute coronary syndromes. Circulation 2005, 111(16):2042-2049.

7. Kwok CS, Tiong D, Pradhan A, Andreou AY, Nolan J, Bertrand OF, Curzen N, Urban P, Myint PK, Zaman AG et al: Meta-Analysis of the Prognostic Impact of Anemia in Patients Undergoing Percutaneous Coronary Intervention. Am J Cardiol 2016, 118(4):610-620.

8. Wester A, Attar R, Mohammad MA, Andell P, Hofmann R, Jensen J, Szummer K, Erlinge D, Koul S: Impact of Baseline Anemia in Patients With Acute Coronary Syndromes Undergoing Percutaneous Coronary Intervention: A Prespecified Analysis From the VALIDATE-SWEDEHEART Trial. J Am Heart Assoc 2019, 8(16):e012741.

9. Lee PC, Kini AS, Ahsan C, Fisher E, Sharma SK: Anemia is an independent predictor of mortality after percutaneous coronary intervention. J Am Coll Cardiol 2004, 44(3):541-546.

10. Nikolsky E, Aymong ED, Halkin A, Grines CL, Cox DA, Garcia E, Mehran R, Tcheng JE, Griffin JJ, Guagliumi $\mathrm{G}$ et al: Impact of anemia in patients with acute myocardial infarction undergoing primary percutaneous coronary intervention: analysis from the Controlled Abciximab and Device Investigation to Lower Late Angioplasty Complications (CADILLAC) Trial. J Am Coll Cardio/ 2004, 44(3):547-553.

11. Mehran R, Dangas G, Abizaid AS, Mintz GS, Lansky AJ, Satler LF, Pichard AD, Kent KM, Stone GW, Leon MB: Angiographic patterns of in-stent restenosis: classification and implications for long-term outcome. Circulation 1999, 100(18):1872-1878.

12. Geng N, Su G, Wang S, Zou D, Pang W, Sun Y: High red blood cell distribution width is closely associated with in-stent restenosis in patients with unstable angina pectoris. BMC Cardiovasc Disord 2019, 19(1):175.

13. Catakoglu AB, Aytekin S, Sener M, Kurtoglu H, Celebi H, Demiroglu IC, Aytekin V: Impact of anemia on nonfatal coronary events after percutaneous coronary interventions. Heart Vessels 2007, 22(6):383388.

14. Humar R, Kiefer FN, Berns H, Resink TJ, Battegay EJ: Hypoxia enhances vascular cell proliferation and angiogenesis in vitro via rapamycin (mTOR)-dependent signaling. FASEB J 2002, 16(8):771-780.

15. Agema WR, Jukema JW, Pimstone SN, Kastelein JJ: Genetic aspects of restenosis after percutaneous coronary interventions: towards more tailored therapy. Eur Heart $J$ 2001, 22(22):20582074. 
16. Brasen JH, Kivela A, Roser K, Rissanen TT, Niemi M, Luft FC, Donath K, Yla-Herttuala S: Angiogenesis, vascular endothelial growth factor and platelet-derived growth factor-BB expression, iron deposition, and oxidation-specific epitopes in stented human coronary arteries. Arterioscler Thromb Vasc Biol 2001, 21(11):1720-1726.

17. Hytonen JP, Taavitsainen J, Laitinen JTT, Partanen A, Alitalo K, Leppanen O, Yla-Herttuala S: Local adventitial anti-angiogenic gene therapy reduces growth of vasa-vasorum and in-stent restenosis in WHHL rabbits. J Mol Cell Cardiol 2018, 121:145-154.

18. Mozos I: Mechanisms linking red blood cell disorders and cardiovascular diseases. Biomed Res Int 2015, 2015:682054.

19. Giustino G, Kirtane AJ, Baber U, Genereux P, Witzenbichler B, Neumann FJ, Weisz G, Maehara A, Rinaldi MJ, Metzger C et al: Impact of Anemia on Platelet Reactivity and Ischemic and Bleeding Risk: From the Assessment of Dual Antiplatelet Therapy With Drug-Eluting Stents Study. Am J Cardiol 2016, 117(12):1877-1883.

20. Lee MS, David EM, Makkar RR, Wilentz JR: Molecular and cellular basis of restenosis after percutaneous coronary intervention: the intertwining roles of platelets, leukocytes, and the coagulation-fibrinolysis system. J Pathol 2004, 203(4):861-870.

21. Yang A, Pizzulli L, Luderitz B: Mean platelet volume as marker of restenosis after percutaneous transluminal coronary angioplasty in patients with stable and unstable angina pectoris. Thromb Res 2006, 117(4):371-377.

22. Zhao J, Wang X, Wang H, Zhao Y, Fu X: Occurrence and predictive factors of restenosis in coronary heart disease patients underwent sirolimus-eluting stent implantation. Ir J Med Sci 2020.

23. Roy P, Okabe T, Pinto Slottow TL, Steinberg DH, Smith K, Torguson R, Xue Z, Gevorkian N, Satler LF, Kent KM et al: Correlates of clinical restenosis following intracoronary implantation of drug-eluting stents. Am J Cardiol 2007, 100(6):965-969.

24. Kastrati A, Dibra A, Mehilli J, Mayer S, Pinieck S, Pache J, Dirschinger J, Schomig A: Predictive factors of restenosis after coronary implantation of sirolimus- or paclitaxel-eluting stents. Circulation 2006, 113(19):2293-2300.

25. Cohen DJ, Doucet M, Cutlip DE, Ho KK, Popma JJ, Kuntz RE: Impact of smoking on clinical and angiographic restenosis after percutaneous coronary intervention: another smoker's paradox? Circulation 2001, 104(7):773-778.

26. Gilbert J, Raboud J, Zinman B: Meta-analysis of the effect of diabetes on restenosis rates among patients receiving coronary angioplasty stenting. Diabetes Care 2004, 27(4):990-994.

27. Abizaid A, Kornowski R, Mintz GS, Hong MK, Abizaid AS, Mehran R, Pichard AD, Kent KM, Satler LF, $\mathrm{Wu} \mathrm{H}$ et al: The influence of diabetes mellitus on acute and late clinical outcomes following coronary stent implantation. J Am Coll Cardiol 1998, 32(3):584-589.

28. Aoyama Y, Hirayama H, Ishii H, Kobayashi K, Ishikawa K, Takigawa M, Nanasato M, Yoshida Y, Aoyama T, Yoshikawa D et al: Impact of chronic kidney disease on a re-percutaneous coronary intervention for sirolimus-eluting stent restenosis. Coron Artery Dis 2012, 23(8):528-532. 
29. Best PJ, Berger PB, Davis BR, Grines CL, Sadeghi HM, Williams BA, Willerson JT, Granett JR, Holmes $\mathrm{DR}$, Jr., Investigators $\mathrm{P}$ : Impact of mild or moderate chronic kidney disease on the frequency of restenosis: results from the PRESTO trial. J Am Coll Cardiol 2004, 44(9):1786-1791.

\section{Figures}

\section{ROC Curve}

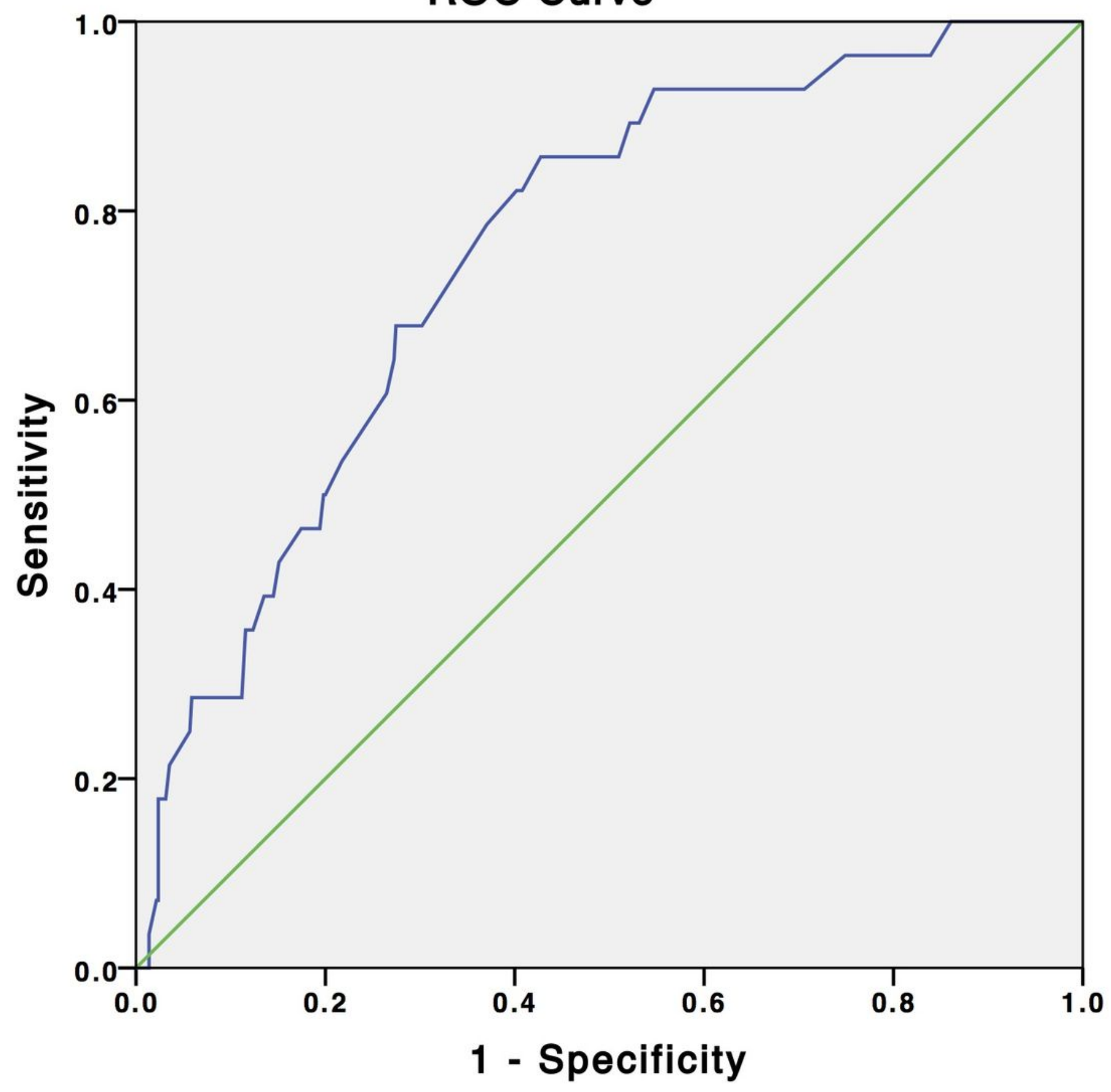

Figure 1 
The ROC curve analysis of $\mathrm{Hb}$ for predicting ISR. ISR, in-stent restenosis; $\mathrm{Hb}$, hemoglobin; ROC, receiver operating characteristic. 